\title{
In Vitro Biopharmaceutical Equivalence of Carbamazepine Sodium Tablets Available in Lima, Peru
}

\author{
Angel T. Alvarado ${ }^{1 *}$, Ana María Muñoz ${ }^{2}$, María R. Bendezú ${ }^{3}$, Juan J. Palomino-Jhong ${ }^{3}$, Jorge A. \\ García ${ }^{3}$, César André Alvarado ${ }^{4}$, Erick A. Alvarado ${ }^{4}$, Gaby Ochoa-Pachas ${ }^{5}$, Mario Pineda-Pérez ${ }^{5}$, \\ and Mario Bolarte ${ }^{5}$ \\ ${ }^{1}$ International Network for Research in Pharmacology and Precision Medicine, School of Human Medicine, San \\ Ignacio de Loyola University, Lima, Peru. \\ ${ }^{2}$ Research Unit in Nutrition, Health, Functional Foods and Nutraceuticals, Universidad San Ignacio de Loyola, Lima \\ Peru. \\ ${ }^{3}$ Faculty of Pharmacy and Biochemistry, San Luis Gonzaga National University of Ica, Ica, Peru. \\ ${ }^{4}$ Faculty of Human Medicine, University of San Martín de Porres, Lima, Peru. \\ ${ }^{5}$ Peruvian Association of Immunogenomics and Personalized Medicine, Lima, Peru.
}

e-mail: eaa.alvarado@hotmail.com

\section{ABSTRACT}

Carbamazepine is an antiepileptic iminostilbene that is dispensed from multiple sources in Peru without bioequivalence studies. The biopharmaceutical equivalence of two generic ( $A$ and $B$ ) and one commercial brand (C) of carbamazepine sodium as compared to the innovator drug was determined by an in vitro study of commercial 200-mg tablets, following the guidelines of the Biopharmaceutical Classification System. Hardness, weight, friability, and content were evaluated for compliance with official specifications. A United States Pharmacopeia (USP) dissolution apparatus 2 (paddle) was used at with $900 \mathrm{~mL}$ of medium (pH 1.2, 4.5, and 6.8) at $75 \mathrm{rpm}$ and 37 $\pm 0.5^{\circ} \mathrm{C}$. Samples $(5 \mathrm{~mL})$ were withdrawn at $5,10,15,30,45,60$, and 90 minutes and analyzed in a UV spectrophotometer at $288 \mathrm{~nm}$. The studied drugs did not release $85 \%$ of the active pharmaceutical ingredient within 30 minutes in any media. When compared to the innovator brand using the similarity factor $\left(f_{2}\right)$, product $\mathrm{A}$ was $<50$ at all three $\mathrm{pH}$ levels; B was $<50$ at $\mathrm{pH}$ 4.5, and $\mathrm{C}$ was $<50$ at $\mathrm{pH} 1.2$ and 4.5. For all products, dissolution efficiency was $56.1-84.3 \%$ and mean dissolution time was $18.0-47.5 \mathrm{~min}$. Despite meeting the official specifications for quality control tests, the evaluated samples are not in vitro biopharmaceutical equivalents with the innovator brand based on the dissolution profiles $\left(f_{2}<50\right)$.

KEYWORDS: Quality control, carbamazepine, bioequivalent drugs, drug interchangeability, dissolution

\section{INTRODUCTION}

Relative bioavailability studies demonstrate the bioequivalence of high health risk drugs that belong to class 2 (low solubility and high permeability) and class 4 (low solubility and low permeability) $(1,2)$. Through in vitro studies, the bioequivalence of class 1 (high solubility and high permeability) and class 3 (high solubility and low permeability) drugs is demonstrated, according to the Biopharmaceutical Classification System (BCS) using three dissolution media at $\mathrm{pH} 1.2, \mathrm{pH} 4.5$ and $\mathrm{pH} 6.8(2-4)$. In vitro dissolution tests must simulate the physiological conditions of the gastrointestinal tract to predict optimal absorption (5). Carbamazepine (5-Hdibenzazepine-5-carboxamide) is an iminostilbene-type class 2 drug derived from tricyclic antidepressants, with a pKa of 2.3 due to the $\mathrm{N}$ of the dibenzazepine ring and a pKa of 13.9 due to the free $\mathrm{NH}_{2}$ group of the carboxamide $(6,7)$. So, in vitro bioequivalence studies do not apply but in vitro biopharmaceutical equivalence studies can be used to evaluate the biopharmaceutical phase of the tablets, following the BCS guidelines for class 1 and 3. The BCS 
for class 1 indicates that the test drug as the reference must be very fast-dissolving or fastdissolving, releasing more than $85 \%$ of the active pharmaceutical ingredient (API) in $\leq 15$ or 30 minutes, respectively. For very fast-dissolving class 3 drugs, it is stated that they should release the at least $85 \%$ of the API in $\leq 15$ minutes $(2,4)$. In vitro biopharmaceutical equivalence studies evaluate disintegration, disaggregation, and dissolution; these processes are determined by hardness and other technological production processes $(1,3)$; therefore, hardness, weight variation, friability, disintegration, concentration quality, and content uniformity should be studied (8-11). This makes it possible to demonstrate the interchangeability of class 2 drugs because their performance is demonstrated through the dissolution profiles, and with thorough quality control tests, defects in the standards established in international pharmacopeias are detected $(3,8)$.

The General Directorate of Medicines, Supplies, and Drugs of Peru has documented the existence of counterfeit and unregistered medicines of different commercial and generic brands (12). It has been established that counterfeit drugs can be without API, with insufficient amounts of API, and with counterfeit packaging (11). As there are generic drugs of doubtful origin and low quality, they are questioned by specialist doctors. This is a global public health problem, which is why the World Health Organization (WHO) has documented and analyzed that there are counterfeit, lowquality drugs and some lack health registration (13). China and India are the countries that commercialize raw materials in bulk to produce low-quality drugs (14).

In Peru, there is a lack of in vitro and in vivo bioequivalence studies, so it has been decided to evaluate the carbamazepine tablets, which are part of the list of essential drugs of the Ministry of Health, for the following reasons: immediate-release carbamazepine tablets are available in the Peruvian pharmaceutical market, carbamazepine has a narrow therapeutic margin; it is considered a low-quality drug; it is a BCS class 2 drug; and to detect adulterated or falsified drugs. To our knowledge, there has not been a bioequivalence study with immediate-release carbamazepine tablets that demonstrates the interchangeability of multi-source drugs with the innovator.

The objective of this research was to determine the biopharmaceutical equivalence of three different brands of carbamazepine sodium tablets compared to the innovator drug, which are prescribed in Lima, Peru, through an in vitro dissolution study, following the guidelines of the BCS and USP. As a statistical indicator of equivalence, similarity factor $\left(f_{2}\right)$ and dissolution efficiency were calculated. Also, the purpose of this work is to encourage the application of relative bioavailability and in vitro bioequivalence studies, which allow for demonstration of therapeutic equivalence of generic and commercial brand drugs with the innovator brand, guaranteeing interchangeability in clinical practice.

\section{MATERIALS AND METHODS}

\section{Chemicals and Reagents}

The reagents were analytical grade and ACS (American Chemical Society) quality including $36 \%$ hydrochloric acid, $96 \%$ ethanol, sodium hydroxide, and monobasic potassium phosphate. A USP carbamazepine standard was used. Chromafil syringe filters of size $25 \mathrm{~mm}$ and pore of $0.45-\mu \mathrm{m}$ $(0.45-\mu \mathrm{m} / 25 \mathrm{~mm})$ were used. All substances and reagents were purchased from Mercantil Laboratory SAC (Lima, Peru). 


\section{Samples}

The sample size consisted of 200 tablets of each 200-mg brand of carbamazepine including two generic brands, one commercial brand, and the innovator product. The generic products were designated as "A" (Bot, Lot L929171205, RS N EE01867, exp. date 12/2021) and "B" (Drock, Lot 102339, RS EE-03825, exp. date 02/2022), the commercial brand was designed as "C" (IQF, Lot 11226348, RS EN 04065, exp. date 12/2022), and the innovator product was designated as " $R$ " (Tegretol, Novartis, Lot 1907751, RS NE-20882, exp. date 01/2021). Product A was purchased in a Ministry of Health hospital pharmacy, and products B, C, and the innovator were purchased in a pharmacy in Lima, Peru.

\section{Method Validation and Calibration}

The dissolution method was validated with $50-\mathrm{mg}$ propylthiuracil tablets by UV-Vis spectrophotometry (5OBIO, Varian Medical Systems) at a wavelength of $288 \mathrm{~nm}$. The specificity was evaluated to determine the interference of excipients in the tablet formulations with respect to the active pharmaceutical ingredient (API). Linearity was determined in the range of 1.60-7.75 $\mu \mathrm{g} / \mathrm{mL}$ with an $R^{2}$ 0.9998. Precision was evaluated with six tablets on 2 days, observing no significant differences $(p=0.064)$. The test for filtration influence showed that the filter does not adsorb the API and there is no interference $(p=0.32)$, so its use in the experimental process is acceptable.

According to the internal calibration sheet of the UV/Vis spectrophotometer, it has passed the diagnosis of photometric accuracy, linearity, noise, stability, diffuse light, and resolution. The dissolution tester (EDT-08Lx, Electrolab) has been calibrated (the same as performed once a year with USP Prednisone Tablets [disintegrating] and with USP Salicylic Acid Tablets [nondisintegrating] in purified water degassed and in degassed $0.05 \mathrm{M} \mathrm{pH} 7.40 \pm 0.05$ phosphate buffer at $37 \pm 0.5{ }^{\circ} \mathrm{C}$ for $30 \mathrm{~min}$ ). The isothermal medium (water bath) was calibrated in two stages: operation and performance. The operation of the switch was verified and the temperature was set at $37{ }^{\circ} \mathrm{C}$. The distribution of heat in the water bath was observed with distilled water in the external container and degassed purified water inside the glass until reaching and maintaining the optimum temperature of $37 \pm 0.5{ }^{\circ} \mathrm{C}$. It was concluded that the water bath equipment heats homogeneously by thermal convection of the water. These procedures are located in the Laboratory of Chemistry and Instrumental Analysis, Department of Chemistry of the San Luis Gonzaga National University of Ica-Peru.

\section{In Vitro Biopharmaceutical Tests \\ Hardness}

In the BIOBASE THAT-3 digital durometer, the force (kgf) necessary to cause rupture was measured for 20 tablets individually from each study sample. The acceptable limit was $6 \pm 2 \mathrm{kgf}$ $(11,15)$.

\section{Weight}

Twenty tablets of each formulation were randomly selected then individually weighed on a Boeco BBL31 analytical balance. The acceptance criterion being a standard deviation < 5\% (15-18).

\section{Friability}

Twenty tablets of each brand were weighed and placed in the Erweka TADR friabilizer drum at 25 rpm for $4 \mathrm{~min}$, then the tablets were dusted and weighed. The difference in the two weights was used to calculate the friability, using the following formula: $(I w-F w) / I w \times 100 \%$ where $I w=$ 
initial weight and $F w=$ final weight of the tablets. The tablet complies with the test according to USP if tablets lose less than $1 \%$ of their weight $(11,15-19)$.

\section{Content}

Drug content was determined by the USP method and Volonté et al. using the UV/Vis spectrophotometer $(15,17,20-22)$. First, 20 carbamazepine tablets were individually weighed and immediately ground to fine powder. Second, $60 \mathrm{mg}$ of carbamazepine powder was weighed and transferred to a $100-\mathrm{mL}$ volumetric flask. Next, $50 \mathrm{~mL}$ of $96 \%$ ethanol was added, mixed, sonicated or $15 \mathrm{~min}$, and allowed to cool to room temperature. Then, it was diluted and completed to volume with $96 \%$ ethanol, and before each reading it was passed through a membrane filter of $0.45-\mu \mathrm{m}$ porosity, discarding the first $5 \mathrm{~mL}$ of the filtrate. Finally, the absorbances were read in triplicate at a wavelength of $288 \mathrm{~nm}$. Mean absorbance and concentration were obtained to calculate the percentage of carbamazepine in each formulation. A calibration curve with an $R^{2}$ value of 0.999 was applied to calculate the concentration. The USP states that carbamazepine tablets must contain no less than $90.0 \%$ and no more than $110.0 \%$ of the amount specified on the label.

\section{Dissolution Tests}

To perform the dissolution test, 12 tablets of each carbamazepine formulation were placed in a USP dissolution apparatus 2 (paddle) for 90 minutes at $75 \mathrm{rpm}$ and $37 \pm 0.5{ }^{\circ} \mathrm{C}$. The dissolution media were $900 \mathrm{~mL}$ each of hydrochloric acid at $\mathrm{pH} 1.2$, acetate buffer at $\mathrm{pH} 4.5$, and phosphate buffer at $\mathrm{pH} 6.8$.

Deaeration of the dissolution medium was carried out under a vacuum, passing the liquid through a $0.45-\mu \mathrm{m} / 25-\mathrm{mm}$ membrane filter while sonicating in a water bath on a Black UC10 ultrasound. The dissolution tester was programmed to maintain the optimum temperature. Each tablet was weighed and subsequently placed in each of the six containers containing $900 \mathrm{~mL}$ of dissolution medium.

Samples $(5 \mathrm{~mL})$ were extracted through a syringe with a $0.45-\mu \mathrm{m}$ chromafil filter at $5,10,15,30$, 45,60 , and 90 minutes, without replacement of medium. Subsequently, $1 \mathrm{~mL}$ of sample was diluted in a $10-\mathrm{mL}$ vial, being volumetric with the respective medium $(2,4)$. These samples were covered with aluminum foil until analysis. The absorbances were determined by UV/Vis spectrophotometry at a wavelength of $288 \mathrm{~nm}$, and the dissolution medium was used as a blank for each case $(4,8)$. A calibration curve with an $R^{2}$ value of 0.996 was made to calculate the concentration and percentage of content.

\section{Statistical Analysis}

SPSS 23 and Microsoft Office Excel 2007 were used for statistical analysis. As a statistical indicator of the in vitro biopharmaceutical equivalence, the recommendations for in vitro bioequivalence studies were used, such as the similarity factor $\left(f_{2}\right)$, dissolution efficiency (DE), and mean dissolution time (MDT) $(4,5,22)$. DE was determined with the formula: $\left(A \cup C_{o}{ }^{t} \times 100\right) / Q^{\infty} \times t^{\infty}$, where $\mathrm{AUC}_{0}{ }^{t}$ is the area under the release curve from the initial time to the final time of the experiment; $Q^{\infty}$ is the mean amount of the drug obtained at the end time of the experiment; $t^{\infty}$ is the end time of the experiment. The mean dissolution time (MDT) was estimated with the formula: $\sum i t i \Delta Q(t i) / Q^{\infty}$, where $\sum i t i \Delta Q(t i)$ is the sum of the difference in time and mean amount of drug; $Q^{\infty}$ is the mean amount of the drug obtained at the end of the experiment $(4,8,18,23)$. Analysis of variance (ANOVA) was performed including the drug and $\mathrm{pH}$ as independent variables (23); and Dunnett's test was used to compare the innovator with the other formulations. A $p$ 
value $<0.05$ was considered significant $(4,8)$.

\section{RESULTS}

\section{Hardness, Weight, Friability, and Content Tests}

Results of the hardness, weight, friability, and content testes are presented in Table 1. Average hardness values were within the acceptance criterion ( $6 \pm 2 \mathrm{kgf}$ ), oscillating in an interval from $1.42 \pm 0.18$ to $2.55 \pm 0.09 \mathrm{kgf}$. Weight variation was acceptable; all products had a standard deviation (SD) of less than $5 \%$, indicating reproducibility within and between batches. Friability test results were within acceptable limits $(<1 \%$ loss due to friction). All formulations met the requirements for drug content (i.e., $90-110 \%$ of the label amount).

Table 1. Physical Characteristics of 200-mg Carbamazepine Immediate-Release Tablets $(n=20)$

\begin{tabular}{|c|c|c|c|c|c|c|}
\hline \multirow[t]{2}{*}{ Product } & \multicolumn{2}{|c|}{ Hardness (< 6 kg-f) } & \multicolumn{2}{|c|}{ Weight (SD < 5\%) } & \multirow{2}{*}{$\begin{array}{c}\text { Friability } \\
(<1 \%)\end{array}$} & \multirow{2}{*}{$\begin{array}{c}\text { Content } \\
(\%)\end{array}$} \\
\hline & Mean \pm SD (kgf) & CV\% & Mean \pm SD (mg) & CV\% & & \\
\hline Generic A & $1.44 \pm 0.12$ & 8.54 & $307.2 \pm 1.7$ & 0.55 & 0.41 & 102.0 \\
\hline Generic B & $2.55 \pm 0.09$ & 3.48 & $357.5 \pm 2.0$ & 0.57 & 0.33 & 103.0 \\
\hline $\begin{array}{c}\text { Commercial } \\
\text { Brand }\end{array}$ & $2.32 \pm 0.20$ & 8.57 & $400.0 \pm 1.6$ & 0.41 & 0.14 & 105.0 \\
\hline Innovator Brand & $1.42 \pm 0.18$ & 12.8 & $295.6 \pm 0.4$ & 0.13 & 0.34 & 102.0 \\
\hline
\end{tabular}

SD: standard deviation; CV\%: coefficient of variation.

\section{Dissolution Tests}

Results of the dissolution tests are presented in Table 2. At pH 1.2, dissolution percentages were < 85\% at $30 \mathrm{~min}$ (A: 75.4\%; B: 52.8\%; C: 31.7\%, R: 47.8\%). At 10 min of dissolution, the coefficient of variation (CV\%) was > 20\% for C (A: $10.46 \%, B: 17.0 \%, C: 24.78 \%$, R: $10.53 \%)$. At 15 min, CV\% was $\geq 10 \%$ for B and C (A: 9.82\%; B: $15.07 \%$; C: $12.15 \%, R: 7.77 \%)$. These results indicate great variability in the dissolution profiles. For class 1 drugs, the CV\% should not be higher than $20 \%$ in the first 10 min and should not exceed than $10 \%$ at other time points (2).

At $\mathrm{pH} 4.5$, the tablets did not release $85 \%$ of the API within 30 min, indicating low solubility at this pH (A: 63.7\%; B: 53.8\%; C: $80.6 \%$, R: $47.1 \%$ ). CV\% did not exceed $20 \%$ at any time point but it was $>10 \%$ at 10 mins for $B$ and $C$ and at several other time points for $B$ and the innovator.

At $\mathrm{pH}$ 6.8, the percentage of drug release was less than $85 \%$ at $30 \mathrm{~min}$ (A: $74.0 \%$; B: $54.3 \%$; C: 48.9\%, R: $48.5 \%$ ). The CV\% was less than $20 \%$ for all products at 10 minutes. After 15 min of dissolution, the $\mathrm{CV} \%$ was highly variable for all products. The CV\% for B was most variable, ranging from $16.99-32.12 \%$ within the first 30 minutes.

The similarity factor, $\mathrm{DE}$, and MDT test results are presented in Table 3 . The $f_{2}$ values were within the range of similarity $\left(f_{2} 50-100 \%\right)$ for product $\mathrm{B}$ at $\mathrm{pH} 1.2(56.7 \%)$ and $6.8(52.4 \%)$ and product $\mathrm{C}$ at $6.8(89.3 \%)$. At $\mathrm{pH} 1.2$ and 4.5 product $\mathrm{C}$ did not reach the minimum value of 50 . Product $\mathrm{A}$ failed to meet the minimum value of $f_{2}$ at all three $\mathrm{pH}$ levels. DE values were above $50 \%$ and MDT was between 18.0 and $47.5 \mathrm{~min}$.

\section{DISCUSSION}

In Peru, it is essential that the 31 generic essential drugs must have therapeutic equivalence studies, so in this study, the in vitro biopharmaceutical equivalence for four products (two generic formulations, one commercial brand, and the innovator brand) carbamazepine (class 2 drug) 
Table 2. Dissolution of 200-mg Carbamazepine Immediate-Release Tablets at $\mathrm{pH} 1.2,4.5$, and 6.8

\begin{tabular}{|c|c|c|c|c|c|c|c|c|c|c|c|c|}
\hline \multirow{2}{*}{$\begin{array}{l}\text { Time } \\
(\min )\end{array}$} & \multicolumn{3}{|c|}{ Innovator Brand } & \multicolumn{3}{|c|}{ Generic A } & \multicolumn{3}{|c|}{ Generic B } & \multicolumn{3}{|c|}{ Commerical Brand } \\
\hline & $\begin{array}{c}\text { Mean } \\
(\%)\end{array}$ & $\begin{array}{c} \pm \\
\text { SD }\end{array}$ & CV\% & $\begin{array}{c}\text { Mean } \\
\text { (\%) }\end{array}$ & $\begin{array}{c} \pm \\
\text { SD }\end{array}$ & CV\% & $\begin{array}{c}\text { Mean } \\
\text { (\%) }\end{array}$ & $\begin{array}{c} \pm \\
\text { SD }\end{array}$ & CV\% & $\begin{array}{c}\text { Mean } \\
(\%)\end{array}$ & $\begin{array}{c} \pm \\
\text { SD }\end{array}$ & CV\% \\
\hline \multicolumn{13}{|c|}{ Dissolution medium: Hydrochloric acid, pH 1.2} \\
\hline 5 & 12.4 & 2.2 & 17.90 & 48.0 & 4.5 & 9.33 & 13.7 & 2.4 & 17.26 & 7.8 & 3.5 & 44.54 \\
\hline 10 & 21.9 & 2.3 & 10.53 & 57.8 & 6.1 & 10.46 & 25.0 & 4.3 & 17.00 & 12.9 & 3.2 & 24.78 \\
\hline 15 & 29.3 & 2.3 & 7.77 & 68.1 & 6.7 & 82 & 37.8 & 5.7 & 5.07 & 8.9 & .3 & .15 \\
\hline 30 & 47.8 & 4.2 & 8.82 & .4 & 9.5 & .63 & 52.8 & 5.7 & 0.69 & 1.7 & 3.6 & 1.35 \\
\hline 45 & 59.1 & 9.0 & 15.25 & 83.0 & 5.6 & 6.71 & 66.1 & 3.2 & 4.77 & 9 & 1.4 & 3.08 \\
\hline 60 & 66.2 & 5.1 & 7.68 & 86.0 & 5.8 & 6.73 & 75.2 & 4.8 & 6.34 & 1.6 & 6.9 & 11.14 \\
\hline 90 & 77.1 & 2.2 & 2.86 & 97.0 & 6.5 & 73 & 88.9 & 4.9 & 5.51 & 3 & 2.4 & 3.06 \\
\hline \multicolumn{13}{|c|}{ ium: Acetate buffer, pH 4.5} \\
\hline 5 & 11.7 & 1.7 & 14.80 & 39.6 & 4.9 & 2.46 & 2.5 & 1.4 & 1.32 & 0.2 & 1.2 & 1.71 \\
\hline 10 & 21.4 & 1.4 & 6.34 & 58.5 & 5.5 & 9.45 & 25.1 & 3.0 & 11.88 & 1.0 & 5.3 & 17.20 \\
\hline 15 & 29.6 & 3.3 & 10.97 & 63.1 & 5.3 & 8.46 & 35.7 & 4.7 & 13.07 & 5 & 4.4 & 9.34 \\
\hline 30 & 47.1 & 3.8 & 8.14 & 63.7 & 3.7 & 5.85 & 53.8 & 5.4 & 10.11 & 0.6 & 6.1 & .52 \\
\hline 45 & 56. & 7.7 & 13.71 & 68.4 & 4.6 & 70 & 70.7 & 3.0 & 4.31 & 7 & .0 & 5.36 \\
\hline 60 & 62.5 & 6.6 & 10.55 & 74.7 & 4.8 & 6.48 & 80.2 & 8.7 & 10.90 & 100.0 & 4.7 & 4.65 \\
\hline 90 & 67.9 & 6.2 & 9.12 & 78.6 & 6.1 & 7.75 & 102.8 & 14.3 & 13.92 & 110.8 & 8.4 & 7.53 \\
\hline \multicolumn{13}{|c|}{ Dissolution medium: Phosphate buffer, pH 6.8} \\
\hline 5 & 12.0 & 1.2 & 9.72 & 42.3 & 5.1 & 2.10 & 3 & 2.4 & 25.52 & 13.0 & 1.2 & 9.16 \\
\hline 10 & 22.2 & 1.5 & 6.96 & 56.8 & 8.7 & 15.37 & 28.1 & 4.8 & 16.99 & 22.5 & 0.5 & 2.22 \\
\hline 15 & 30.1 & 1.4 & 4.52 & 62.4 & 3.6 & 5.83 & 33.6 & 10.8 & 32.12 & 29.0 & 4.0 & 13.75 \\
\hline 30 & 48.5 & 3.3 & 6.88 & 74.0 & 8.3 & 11.18 & 54.3 & 14.2 & 26.19 & 48.9 & 2.8 & 5.63 \\
\hline 45 & 55.9 & 2.6 & 4.69 & 83.2 & 5.1 & 6.11 & 70.0 & 3.7 & 5.32 & 55.7 & 4.1 & 7.32 \\
\hline 60 & 68.8 & 7.5 & 10.87 & 91.5 & 1.0 & 1.13 & 77.4 & 3.2 & 4.09 & 65.2 & 3.7 & 5.66 \\
\hline 90 & 77.0 & 1.8 & 2.34 & 94.6 & 1.3 & 1.33 & 91.2 & 5.0 & 5.46 & 75.5 & 0.7 & 0.90 \\
\hline
\end{tabular}

Table 3. Similarity Factor $\left(f_{2}\right), D E$, and MDT Values for 200-mg Carbamazepine Immediate-Release Tablet Formulations

\begin{tabular}{|c|c|c|c|c|c|c|c|c|c|c|c|c|}
\hline Product & \multicolumn{3}{|c|}{$f_{2}(\%)$} & \multicolumn{3}{|c|}{$A U C_{o}{ }^{t}(\min \%)$} & \multicolumn{3}{|c|}{ DE (\%) } & \multicolumn{3}{|c|}{ MDT (min) } \\
\hline $\mathrm{pH}$ & 1.2 & 4.5 & 6.8 & 1.2 & 4.5 & 6.8 & 1.2 & 4.5 & 6.8 & 1.2 & 4.5 & 6.8 \\
\hline Generic A & 26.3 & 31.2 & 27.8 & 6975 & 5962 & 6957 & 79.9 & 84.3 & 81.7 & 22.9 & 18.0 & 20.9 \\
\hline Generic B & 56.7 & 39.6 & 52.4 & 5380 & 5758 & 5497 & 67.2 & 62.3 & 67.0 & 36.0 & 41.4 & 36.5 \\
\hline $\begin{array}{c}\text { Commercial } \\
\text { Brand }\end{array}$ & 49.6 & 26.3 & 89.3 & 4003 & 7208 & 4637 & 56.1 & 72.3 & 68.2 & 47.5 & 31.0 & 35.2 \\
\hline $\begin{array}{c}\text { Innovator } \\
\text { Brand }\end{array}$ & & & & 4715 & 4438 & 4741 & 67.9 & 72.7 & 68.4 & 35.5 & 30.5 & 34.8 \\
\hline
\end{tabular}

$A \cup C_{o}^{t}$ : area under the curve by the trapezius method, DE: dissolution efficiency, MDT, mean dissolution time.

were evaluated, following the guidelines of the bioequivalence studies in vitro for class 1 and 3 $(4,5,8)$. The hardness test was carried out, with results being within the acceptance criterion $(<6$ $\pm 2 \mathrm{kgf}$ ) for all products, indicating low variability for the same formulation, a fact that shows homogeneity within the batch for each pharmaceutical laboratory. No standard regulates the weight that tablets should have, and it is up to each laboratory to stipulate the weight of these pharmaceutical forms. Based on the reported literature and according to statistics, the standard 
deviation should not be greater than $5 \%$ to ensure reproducibility within and between batches $(23,24)$. All samples investigated in this study fulfilled this criterion. The friability test measures the ability of tablets to resist mechanical shock and abrasion during production, packaging, and transportation, with little loss of the API. In this study, the abrasion values indicate that the tablet surfaces are fragile to handling but there was no evidence of cracked, segmented, or broken tablets for all four products. Also, the drug content of the tablets was within the acceptance range of $90-110 \%$ for all products.

This study also evaluated the dissolution profiles of carbamazepine tablets in three dissolution

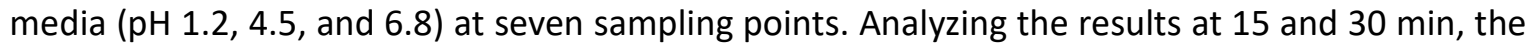
study samples did not release $85 \%$ of the API in all three dissolution media. The CV\% was less than $20 \%$ up to $10 \mathrm{~min}$ for product $\mathrm{A}$ in all three media, for $\mathrm{B}$ only at $\mathrm{pH} 1.2$, and for $\mathrm{C}$ at $\mathrm{pH} 4.5$ and 6.8. After 10 mins, $\mathrm{A}$ and $\mathrm{C}$ showed a CV\% lower than $10 \%$ only at $\mathrm{pH}$ 4.5. The $\mathrm{CV} \%$ was not acceptable for products and in the other dissolution media, reflecting low aqueous solubility (170 $\mathrm{mg} / \mathrm{L})$, which would generate irregular and delayed absorption in vivo and affect bioavailability (25-27).

It is well known that the manufacture, formulation, polymorphism of the drug, and the type and quantity of excipients can influence the dissolution process. For example, Block et al. demonstrated that in the wet granulation process, the amount and type of excipient used in the technological manufacture of metformin tablets influences the dissolution profile (27). Battu et al. reported that disintegrants and cross-linked polymers that swell in contact with water influence disintegration of the pharmaceutical form (28). Ghayas et al. showed that the compression force, mixing time, formulation, and amount of disintegrant and lubricant influence dissolution and bioavailability of the API (29). In the case of carbamazepine, Murphy et al. observed that carbamazepine has four anhydrous polymorphic forms and one stable dihydrate form, with the anhydrous polymorphic form III more soluble $(380 \mathrm{mg} / \mathrm{L})$ than the dihydrate form $(130 \mathrm{mg} / \mathrm{L})$ at $25^{\circ} \mathrm{C}(30)$; whereas Tian et al. mentions that, in aqueous solution, polymorphic forms I-III are converted to the dihydrate form (31). To avoid such transformation and improve dissolution and bioavailability of carbamazepine, various technological processes have been proposed. Katzhendler et al. demonstrated that hydroxypropylmethylcellulose (HPMC) inhibits the transformation of carbamazepine form III into the dihydrate form in gels and an aqueous medium due to hydrogen bonding between the drug and polymer (32). Studies by RodríguezHornedo et al. and Li et al. demonstrated that the association of succinic acid (SUC, pKa 4.21 and 5.64) with carbamazepine form the cocrystal (carbamazepine-succinic, CBZ-SUC), which is more soluble than the dihydrate form at $\mathrm{pH} 3(33,34)$. Although crystal pharmaceuticals can provide a better dissolution profile and, therefore, adequate bioavailability of the drug, recrystallization of the drug during the dissolution of the cocrystal has been observed (35). Markopoulos et al. and Dressman et al. demonstrated that $\mathrm{pH}$ of the dissolution medium influences the dissolution processes of drugs and bioavailability $(5,36)$. The physiological appearance of the intestinal mucosa, the allelic variants CYP2C9*2 and CYP2C9*3, and the metabolic phenotype of the patients, which influence the bioavailability and efficacy of carbamazepine, should also be considered (37).

In the present study, the $f_{2}$ was used as a statistical indicator for similarity of the generic and commercial products with the innovator brand, with acceptable values being $50-100 \%$. Only product $\mathrm{B}$ had an $f_{2}$ value greater than 50 at $\mathrm{pH} 1.2$ and 6.8 , and product $\mathrm{C}$ was acceptable at $\mathrm{pH}$ 6.8. Based on $f_{2}$ values $<50$ at the three $\mathrm{pH}$ levels, in vitro biopharmaceutical equivalents could not be established for products $A-C$ with the innovator brand. When comparing the $D E$ values, 
only product $\mathrm{A}$ was greater than $80 \%$ in the three $\mathrm{pHs}$, whereas the other products were greater than $50 \%$ and variable at the different $\mathrm{pH}$ levels $(4,38)$. Low DE indicates that there would be an amount of drug dissolved in the dissolution medium while in contact with the gastrointestinal mucosa where it would be absorbed, but drug release did not exceed $80 \%$ uniformly in the three dissolution media (3).

The MDT represents the time at which $63.2 \%$ of the in vitro dose dissolves before $20 \mathrm{~min}$. In this study, we observed that the MDT values are above 20 min (except for product $A$, which has a value of $18 \mathrm{~min}$ at $\mathrm{pH} \mathrm{4.5),} \mathrm{and} \mathrm{when} \mathrm{correlating} \mathrm{these} \mathrm{values} \mathrm{in} \mathrm{vitro} \mathrm{with} \mathrm{mean} \mathrm{gastric}$ emptying, which is $15-20 \mathrm{~min}$ in a fasted state, the dissolution profile of generic and commercial carbamazepine drugs is slow and variable.

This work has some limitations that must be considered, such as not having evaluated all the generic and commercial brands of carbamazepine tablets that are prescribed and dispensed in Peru, not having carried out the disintegration test, and not having measured the dimensions of tablets, which should be considered in future studies. Notwithstanding the foregoing, this study provides scientific evidence on biopharmaceutical studies and dissolution profiles, which will encourage the implementation of in vivo bioequivalence studies of carbamazepine and the entire list of essential generic drugs of Peru.

\section{CONCLUSION}

This study examined the dissolution profiles of three different brands of 200-mg carbamazepine immediate-release tablets in three dissolution media that simulate the $\mathrm{pH}$ of gastrointestinal fluids. According to the similarity factor $\left(f_{2}\right)$, they are not bioequivalent in vitro with the innovator brand and therefore are not interchangeable, despite meeting the official specifications for quality control tests. Therefore, carbamazepine tablets cannot be exempt from relative bioavailability studies to demonstrate therapeutic equivalence and interchangeability in clinical practice.

\section{FUNDING}

This work was supported by the Peruvian Association of Immunogenomics and Personalized Medicine and San Ignacio de Loyola University School of Human Medicine.

\section{CONFLICTS OF INTEREST}

The authors disclosed no conflicts of interest related to this article.

\section{REFERENCES}

1. Talevi, A.; Quiroga, P.; Ruíz, M.E. Procesos Biofarmacéuticos. Universidad Nacional de la Plata, Editorial Edulp,; 2016, p 157 pag.

2. ICH M9 guideline on biopharmaceutics classification system-based biowaivers; EMA/CHMP/ICH/493213/2018; Committee for Medicinal Products for Human Use (CHMP), European Medicines Agency: London, 2020.

3. Matiz, G. E.; Trujillo, M.; Pérez, D. A.; Baena, Y. [In vitro evaluation of the interchangeability of different brands of diclofenac sodium tablets available in the Colombian market] [in Spanish]. Biomédica. 2018, 38, 486-495. DOI: 10.7705/biomedica. v38i4.3988.

4. Alvarado, A. T.; Muñoz, A. M.; Miyasato, J. M.; Alvarado, E. A.; Loja, B.; Villanueva, L.; Pineda, M.; Bendezú, M.; Palomino-Jhong, J. J.; García, J. A. In Vitro Therapeutic Equivalence of Two Multisource (Generic) Formulations of Sodium Phenytoin (100 mg) Available in Peru. Dissolut. Technol. 2020, 27, 33-40. DOI: 10.14227/DT270420P33. 
5. Markopoulos, C.; Andreas, C. J.; Vertzoni, M.; Dressman, J.; Reppas, C. In-vitro simulation of luminal conditions for evaluation of performance of oral drug products: Choosing the appropriate test media. Eur. J. Pharm. Biopharm. 2015, 93, 173-182. DOI: 10.1016/j.ejpb.2015.03.009.

6. Chbili, C.; Hassine, A.; Laouani, A.; Amor, S. B.; Nouira, M.; Ammou S. B.; Saguem, S. The relationship between pharmacokinetic parameters of carbamazepine and therapeutic response in epileptic patients. Arch med Sci. 2017, 13, 353-360. DOI: 10.5114/aoms.2016.60090.

7. Tolbert, D.; Cloyd, J.; Biton, V.; Bekersky, I.; Walzer, M.; Wesche, D.; Drummond, R; Lee, D. Bioequivalence of oral and intravenous carbamazepine formulations in adult patients with epilepsy. Epilepsia. 2015, 56, 915-923. DOI: 10.1111/epi.13012.

8. Villarroel Stuart, A.; Clement, Y.; Sealy, P.; Löbenberg, R.; Montane-Jaime, L.; Maharaj, R. G.; Maxwell, A. Comparing the dissolution profiles of seven metformin formulations in simulated intestinal fluid. Dissolut. Technol. 2015, 22, 17-21. DOI: 10.14227/DT220115P17.

9. Akpabio, E.; Jackson, C.; Ugwu, C.; Etim, M.; Udofia, M. Quality control and in vitro bioequivalence studies on four brands of ciprofloxacin tablets commonly sold in Uyo Metropolis, Nigeria. J. Chem. Pharm. Res. 2011, 3, 734-741.

10. Hassali, M.A.; Thambyappa, J.; Saleem, F.; Haq, N.; Aljadhey, V. Generic substitution in Malaysia: recommendations from a systematic review. J App Pharm Sci. 2012, 2,159-160. DOI: 10.7324/JAPS.2012.2827.

11. Uddin, M. S.; Mamun, A. A.; Hossain, M. S.; Asaduzzaman, M.; Sarwar, M. S.; Rashid, M.; HerreraCalderon, O. In vitro quality evaluation of leading brands of ciprofloxacin tablets available in Bangladesh. BMC Res Notes. 2017, 10, 185. DOI: 10.1186/s13104-017-2507-y.

12. Directorate General of Drug Supplies and Drugs. [Evaluation list of counterfeit products and their alerts-DIRIS] [in Spanish]. http://www.digemid.minsa.gob.pe/UpLoad/UpLoaded/PDF/ControlYVigilancia/Comerciollegaal/Produ ctosFalsificados/Productos_falsificados_2019_Nacional_diris.pdf. (accessed October 1, 2020).

13. World Health Organization. [Global Surveillance and Monitoring System for Substandard and $\begin{array}{llll}\text { Counterfeit Medical Products] } & \text { Spanish]. }\end{array}$ https://www.who.int/medicines/regulation/ssffc/publications/GSMS_report_SP.pdf. (accessed October 1, 2020).

14. Khan, A.; Ghilzai, N. Counterfeit and substandard quality of drugs: the need for an effective and stringent regulatory control in India and other developing countries. Indian J Pharmacol. 2007, 39, 206-207. DOI: 10.4103/0253-7613.36541.

15. Uduma, E. O.; Ayodeji, A. A.; Rosemary, C. A.; Okorie, O.; Christian, C. O. Bioequivalence studies on some selected brands of ciprofloxacin hydrochloride tablets in the Nigerian market with ciproflox ${ }^{\circledR}$ as innovator brand. J. Appl. Pharm. Sci. 2011, 1, 80-84.

16. Uddin, M. S.; Mamun, A. A.; Tasnu, T.; Asaduzzaman, M. In-process and finished products quality control tests for pharmaceutical tablets according to pharmacopoeias. J Chem Pharm Res. 2015, 7, 180-185.

17. Matiz Melo, G. E.; Rodríguez Cavallo, E. [Comparative study of the biopharmaceutical quality of commercial and generic brands of captopril and losartan tablets in the Colombian market] [in Spanish]. Rev. Colomb. Ciencias Quim. Farm. 2014, 43, 217-233. DOI: 10.15446/rcciquifa.v43n2.54209.

18. Alvarado, A. T.; Muñoz, A. M.; Bendezú, M.; García, J. A.; Palomino-Jhong, J. J.; Ochoa-Pachas, G.; Chonn-Chang, A.; Sullón-Dextre, L.; Loja-Herrera, B.; Pineda-Pérez, M. In vitro biopharmaceutical equivalence of 5 -mg glibenclamide tablets in simulated intestinal fluid without enzymes. Dissolut. Technol. 2021, 28, 1-12. DOI: 10.14227/DT280121PGC2.

19. Tarawneh, O.; Madi, A.; Hamed, R.; Qirem, R.; Qerem, W.; Alhusban, A.; Sunoqrot, S.; Mahmoud, N.; Ata, S.; Alsheikh, I. In vitro characterization and evaluation of commercialized paracetamol products in Jordan. Dissolut. Technol. 2019, 26, 36-44. DOI: 10.14227/DT260119P36.

20. The United States Pharmacopeia and National Formulary USP 35-NF 30; The United States Pharmacopeial Convention, Inc.: Rockville, MD, 2012.

21. The United States Pharmacopeia and National Formulary USP 37-NF 32; The United States 
Pharmacopeial Convention, Inc.: Rockville, MD, 2014.

22. Volonté, M. G.; Viñas, M. A.; Buschiazzo, P. M.; Piersante, M. V.; Escales, M. C.; Gorriti, C. E. [Comparative study of tablets with $200 \mathrm{mg}$ of carbamazepine to determine pharmaceutical equivalence] [in Spanish] Lat. Am. J. Pharm. 2004, 23, 391-397.

23. Podczeck, F. Comparison of in vitro dissolution profiles by calculating mean dissolution time (MDT) or mean residence time (MRT). Int. J. Pharm. 1993, 97, 93-100. DOI: 10.1016/0378-5173(93)90129-4. León, G.; Osorio, M.; Matiz, G. [Comparative biopharmaceutical study of $500 \mathrm{mg}$ acetaminophen tablets available in the Colombian market] [in Spanish] Rev. Cuba. Farm. 2015, 49, 630-640.

24. Bertilsson L. Clinical pharmacokinetics of carbamazepine. Clin Pharmacokinet. 1978, 3, 128-143. DOI: 10.2165/00003088-197803020-00003.

25. Uzunović, A.; Vranić, E.; Hadzidedić, S. Impairment of the in vitro release of carbamazepine from tablets. Bosn. J. Basic Med. Sci. 2010, 10, 234-238. DOI: 10.17305/bjbms.2010.2693.

26. Block, L. C.; Schemling, L. O.; Couto, A. G.; Mourão, S. C.; Bresolin, T. M. B. [Pharmaceutical equivalence of metformin tablets with various binders] [in Spanish] Rev. Cienc. Farm. Basica Apl. 2008, 29, 29-35.

27. Battu, S. K.; Repka, M. A.; Majumdar, S.; Madhusudan, R. Y. Formulation and evaluation of rapidly disintegrating fenoverine tablets: effect of superdisintegrants. Drug Dev. Ind. Pharm. 2007, 33, 12251232. DOI: $10.1080 / 03639040701377888$.

28. Ghayas, S.; Sheraz, M. A.; Anjum, F.; Baig, M. T. Factors influencing the dissolution testing of drugs. Pak. J. Health Res. 2013, 1, 1-11.

29. Murphy, D.; Rodríguez-Cintrón, F.; Langevin, B.; Kelly, R.C.; Rodríguez-Hornedo, N. Solution-mediated phase transformation of anhydrous to dihydrate carbamazepine and the effect of lattice disorder. Int. J. Pharm. 2002, 246, 121-134. DOI: 10.1016/S0378-5173(02)00358-7.

30. Tian, F.; Zeitler, J. A.; Strachan, C. J.; Saville, D. J.; Gordon, K. C.; Rades, T. Characterizing the conversion kinetics of carbamazepine polymorphs to the dihydrate in aqueous suspension using Raman spectroscopy. J. Pharm. Biomed. Anal. 2006, 40, 271-280. DOI: 10.1016/j.jpba.2005.07.030.

31. Katzhendler, I.; Azoury, R.; Friedman, M. Crystalline properties of carbamazepine in sustained release hydrophilic matrix tablets based on hydroxypropyl methylcellulose. J. Control. Release. 1998, 54, 6985. DOI: 10.1016/S0168-3659(98)00002-9.

32. Rodríguez-Hornedo, N.; Murphy, D. Surfactant-facilitated crystallization of dihydrate carbamazepine during dissolution of anhydrous polymorph. J. Pharm. Sci. 2004, 93, 449-460. DOI: 10.1002/jps.10496.

33. Li, M.; Qiao, N.; Wang, K. Influence of sodium lauryl sulfate and tween 80 on carbamazepinenicotinamide cocrystal solubility and dissolution behavior. Pharmaceutics 2013, 5, 508-524. DOI: 10.3390/pharmaceutics5040508.

34. Ullah, M.; Ullah, H.; Murtaza, G.; Mahmood, Q.; Hussain, I. Evaluation of Influence of Various Polymers on Dissolution and Phase Behavior of Carbamazepine-Succinic Acid Cocrystal in Matrix Tablets. BioMed Res. Int. 2015, 2015, 870656. DOI: 10.1155/2015/870656.

35. Dressman, J. B.; Berardi, R. R.; Dermentzoglou, L. C.; Russell, T. L.; Schmaltz, S. P.; Barnett, J. L.; Jarvenpaa, K. M. Upper gastrointestinal (GI) pH in young, healthy men and women. Pharm. Res. 1990, 7, 756-761. DOI: 10.1023/A:1015827908309.

36. Alvarado, A. T.; Muñoz, A. M.; Loja, B.; Miyasato, J. M.; García, J. A.; Cerro, R. A.; Quiñones, L. A.; Varela, N. M. [Study of the allelic variants CYP2C9*2 and CYP2C9*3 in samples of the Peruvian mestizo population] [in Spanish] Biomédica 2019, 39, 601-610. DOI: 10.7705/biomedica.4636.

37. Jung, H.; De Anda, G.; Rubio, K.; Mayet, L. [Comparison of dissolution profiles. Impact of the criteria of different regulatory agencies in the calculation of $f_{2}$ ] [in Spanish] Rev. Mex. Cienc. Farm. 2012, 43, 6771. 